\title{
Hydrothermal Synthesis and Characterization of Copper Glycinate (Bio-MOF-29) and Its in Vitro Drugs Adsorption Studies
}

\author{
Tabinda Sattar, Muhammad Athar \\ Instituite of chemical sciences, B.Z.U Multan, Pakistan \\ Email: athar.qr@gmail.com
}

How to cite this paper: Sattar, T. and Athar, M. (2017) Hydrothermal Synthesis and Characterization of Copper Glycinate (Bio-MOF-29) and Its in Vitro Drugs Adsorption Studies. Open Journal of Inorganic Chemistry, 7, 17-27.

https://doi.org/10.4236/ojic.2017.72002

Received: February 1, 2017

Accepted: March 28, 2017

Published: March 31, 2017

Copyright ( 92017 by authors and Scientific Research Publishing Inc. This work is licensed under the Creative Commons Attribution International License (CC BY 4.0). http://creativecommons.org/licenses/by/4.0/

\begin{abstract}
A new porous compound, Copper glycinate (Bio-MOF-29), $\left[\mathrm{Cu}\left(\mathrm{C}_{2} \mathrm{H}_{4} \mathrm{NO}_{2}\right)_{2}\right.$ $\left(\mathrm{H}_{2} \mathrm{O}\right)$ ] has been synthesized by the hydrothermal method and characterized by single crystal XRD analysis. Bio-MOF-29 crystallized in orthorhombic crystal system with $P 2_{1} 2_{1} 2_{1}$ space group. In vitro adsorption studies of four different drugs, terazosine hydrochloride, telmisartan, glimpiride and rosuvastatin have been carried out for Bio-MOF-29. Drugs adsorption estimations of drugs loaded Bio-MOF-29 have been carried out through High Performance Liquid Chromatography (HPLC), which reveals that these drugs are successfuly adsorbed in it. Also the slow release of adsorbed drugs after intervals was observed through HPLC. Thermograms and powder XRD patterns of Bio-MOF-29 before and after drugs adsorption were also recorded to elaborate the phenomenon of drugs adsorption in Bio-MOF-29.
\end{abstract}

\section{Keywords}

Bio-Metal Organic Framework, Glycine, Single Crystal XRD Analysis, High Performance Liquid Chromatography, Terazosine $\mathrm{HCl}$, Telmisartan, Glimpiride, Rosuvastatin, Bio-MOF-29

\section{Introduction}

In the interim of the last decade of $20^{\text {th }}$ century, the metal organic frameworks (MOFs), due to their porosity and multifunctional properties have been of great interest to the researchers [1] [2] [3] [4] [5]. With the passage of time, new discoveries have been made in this field. The use of nitrogen based ligands is getting more importance to construct the MOFs due to their greater potential for gases as well as drugs storage [6] [7] [8] [9] [10]. Use of amino acids as linker molecules is also a new strategy to develop such frameworks with potential utili- 
ty for the storage of drugs [11] [12] [13]. While designing the synthesis of new MOFs for use in drug delivery, two important factors such as non-toxicity and biocompatibility should be considered. Therefore, use of the metal cations like copper, nickel, manganese etc. and bio-linker molecules such as amino acids for the construction of MOFs will prove beneficial in the field of drug delivery [14] [15] [16] [17] [18].

J. An et al. have reported the construction of Bio-MOF-1 which is actually the representative of the series of recently discovered class of bio-metal organic frameworks (Bio-MOFs) [19] [20] [21]. Successful drug adsorption and release phenomenon have been investigated through Bio-MOF-1. Strong ionic interaction between the drug and the framework of Bio-MOF-1 has supported the idea that drugs can be successfully entraped and delivered from such frameworks. Furthermore, Bio-MOFs have also been reported for their gas storage property [22] [23] [24] [25].

Recent studies are based on the synthesis of a new bio-MOF in which nitrogen based glycine has been used as a linker molecule and copper metal is used as a connector to construct the framework. This newly synthesized Bio-MOF-29 has been characterized and evaluated for its procainamide hydrochloride adsorption property. In vitro drug adsorption in this compound will open new gateways for in vivo drug adsorption which will be beneficial for the sake of mankind [25].

\section{Results and Discussions}

The new material has been synthesized hydrothermally and named as Bio-MOF29 because it is the metal organic framework based on bio molecule (glycine) as a linker and copper metal with atomic number 29. Structure of Bio-MOF-29 has been assessed by the single crystal XRD analysis and its drug adsorption property has been evaluated by means of TGA, XRD and HPLC studies.

\subsection{Crystallographic Data and Structure Refinement}

An X-ray crystal structure of Bio-MOF-29 was determined on a Bruker Smart Apex II CCD area detector diffractometer with graphite-monochromated $\mathrm{MoK}_{\alpha}$ $(\lambda=0.71073 \AA$ ) radiation [26]. A single crystal was mounted on a glass capillary and data were colected at $273 \mathrm{~K}$. For the sake of the data collection and refinements all computer programs used are contained in the Bruker program packages Smart, Saint and SHELXTL.

The structure was solved by direct method, which located the positions of copper atoms and most of non hydrogen atoms. Remaining non hydrogen atoms were located and expanded by using subsequent Fourier transformation techniques. Final difference Fourier syntheses showed only chemically insignificant electron density (largest difference peak $0.97 \AA$ ). . Hydrogen atoms were placed in idealized positions. All non hydrogen atoms were refined anisotropically and refined by a full-matrix least-square calculation on F2 with the aid of program SHELXL97 (Sheldrick 1997).

Unit-cell parameters and systematic absences based on $E$-values and the suc- 
cessful solution and refinement indicated that Bio-MOF-29 crystallized in orthorhombic crystal system with $P 2_{1} 2_{1} 2_{1}$ space group. Unit cell dimensions were derived from the least squares fit of the angular settings of 1260 reflections from the data collection. Data reduction was performed by using SAINT program.

The compound crystallized in one-dimensional crystal lattice. In each asymmetric unit, $\mathrm{Cu}$ cation is coordinated to one water molecule and two bidentate glycinate ligands. One of the glycinate anion is chelated to the copper cation by its nitrogen atom and one of oxygen atoms thus stablizing its five membered ring. The other glycinate ligand coordinate with copper in a square plane through $\mathrm{N}$ as well as $\mathrm{O}$-atom, this ligand also acts as a linker due to bridging mode of the other $\mathrm{O}$-atom and thus completing distorted octahedral geometry around the $\mathrm{Cu}$-atoms. ORTEP drawing of the new material, Bio-MOF-29 has been shown below as Figure 1.

$\mathrm{Cu}-\mathrm{O}$ bond lengths are 1.874(4) $\AA$ f for $\mathrm{Cu}(1)-\mathrm{O}(1)$ and 1.885(4) $\AA$. for $\mathrm{Cu}(1)$ $\mathrm{O}(3) . \mathrm{Cu}-\mathrm{N}$ bond lengths are 1.931(5) $\AA$ f for $\mathrm{Cu}(1)-\mathrm{N}(1)$ and 1.913(5) $\AA$ for $\mathrm{Cu}(1)-\mathrm{N}(2)$. The $\mathrm{O}-\mathrm{Cu}-\mathrm{O}$ bond angles are $93.21(17)^{\circ}$ for $\mathrm{O}(1)-\mathrm{Cu}(1)-\mathrm{O}(3)$, $89.2(2)^{\circ}$ for $\mathrm{O}(1)-\mathrm{Cu}(1)-\mathrm{O}(5)$ and $91.31(18)^{\circ}$ for $\mathrm{O}(3)-\mathrm{Cu}(1)-\mathrm{O}(5)$. Whereas $\mathrm{N}-$ $\mathrm{Cu}-\mathrm{O}$ bond angles for glycinates are $84.8(2)^{\circ}$ for $\mathrm{O}(1)-\mathrm{Cu}(1)-\mathrm{N}(1)$ and $84.79(18)^{\circ}$ for $\mathrm{O}(3)-\mathrm{Cu}(1)-\mathrm{N}(2)$.

One dimensional growth of the crystal lattice has been shown in Figure 2. These one dimensional pillars are packed in the crystal lattice maintaining certain spaces through hydrogen bonding. This arrangement results in the developement of pores, which are available for the storage purposes of drug molecules.

CCDC-1405986 contains the supplementary crystallographic data for this paper. The data can be obtained free of cost from the Cambridge Crystallographic Data Centre, 12 Union Road Cambridge CB21EZ, UK (fax: (+44)1223-336-033; or E-mail: deposit@ccdc.cam.ac.uk).

The cryatal data parameters have been summarized in Table 1 .

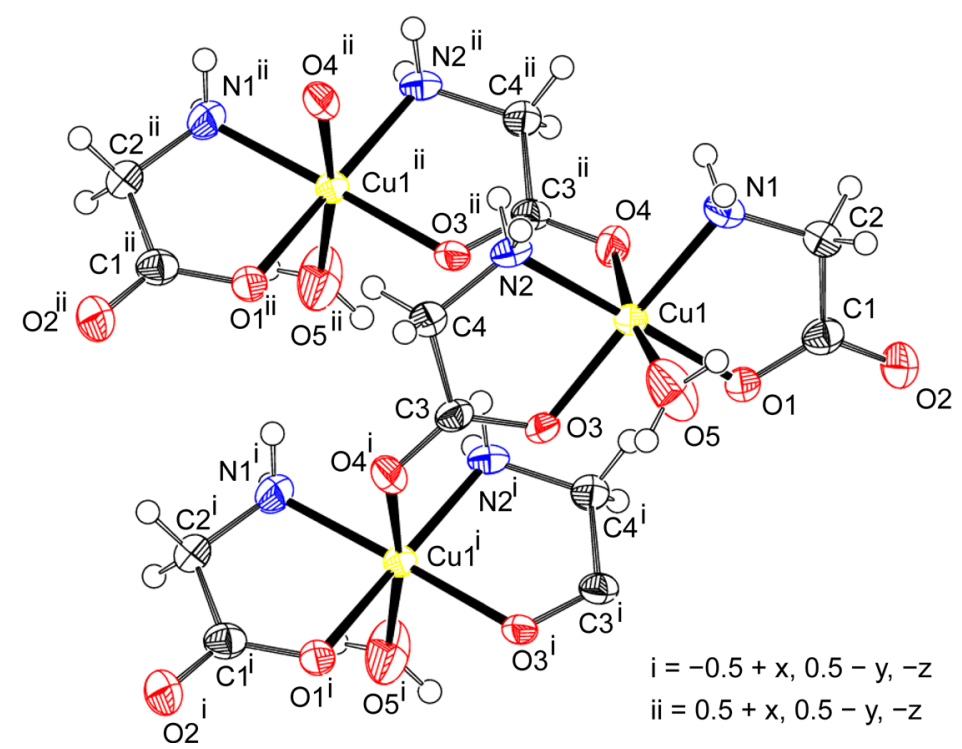

Figure 1. ORTEP drawing of Bio-MOF-29 showing the polymeric nature. 


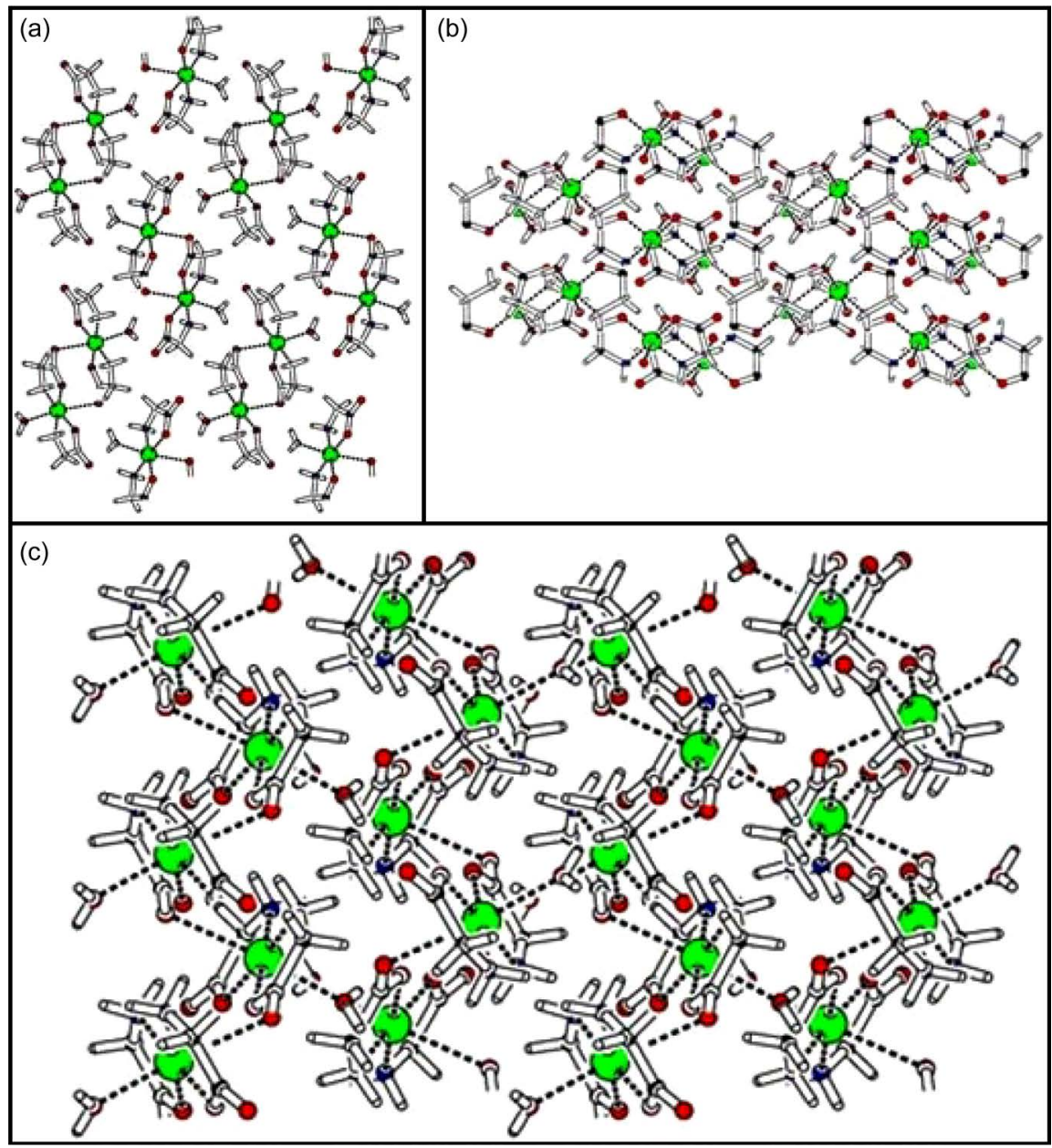

Figure 2. Structural view of Bio-MOF-29 along (a), (b) and (c) axes.

\subsection{Drugs Adsorption in Bio-MOF-29}

In vitro drug adsorption studies in copper glycinate (Bio-MOF-29) were carried out using four drugs namely terazosine hydrochloride, telmisartane, glimpiride and rosuvastatin.

Terazosine hydrochloride (Hytrin) and telmisartan are used to treat hypertension (high blood pressure), glimpiride is used to control the blood sugar levels in body and rosuvastatin (crestor) is used in combination with exercise diet and weight loss to treat high cholesterol. So their successful in vitro drugs adsorption and release experiments will lead towards the use of these drugs for in vivo studies as well.

These drugs were loaded into Bio-MOF- 29 by soaking the synthesized compound in the drugs solution. TGA and powder XRD patterns of Bio-MOF-29 before and after drug loading were compared. Furthermore HPLC studies were carried out to determine the amount of drugs loaded and to observe its release pattern.

\subsection{Thermogravimetric Studies}

SDT Q600 thermo gravimetric analyzer was used to record the thermograms of 
Table 1. Summary of crystal data for Bio-MOF-29.

\begin{tabular}{|c|c|}
\hline Empirical formula & $\mathrm{C}_{4} \mathrm{H}_{10} \mathrm{~N}_{2} \mathrm{O}_{5} \mathrm{Cu}$ \\
\hline Formula weight & 229.68 \\
\hline Temperature & $273(2) \mathrm{K}$ \\
\hline Wavelength & $0.71073 \AA$ \\
\hline Crystal system, space group & Orthorhombic, $P 2_{1} 2_{1} 2_{1}$ \\
\hline Unit cell dimensions & $\begin{array}{l}\mathrm{a}=5.0212(7) \AA \\
\mathrm{b}=10.4206(14) \AA \\
\mathrm{c}=13.0071(16) \AA\end{array}$ \\
\hline Volume & $680.58(16) \mathrm{A}^{3}$ \\
\hline D, calculated & $6,2.242 \mathrm{Mg} / \mathrm{m}^{3}$ \\
\hline $\mathrm{F}(000)$ & 468 \\
\hline Crystal size & $0.59 \times 0.22 \times 0.05 \mathrm{~mm}$ \\
\hline Theta range for data collection & $2.50^{\circ}$ to $27.998^{\circ}$ \\
\hline Limiting indices & $\begin{array}{l}-6<=\mathrm{h}<=6 \\
-13<=\mathrm{k}<=10 \\
-14<=1<=17\end{array}$ \\
\hline Reflections collected/unique & $4782 / 1644[\mathrm{R}(\mathrm{int})=0.0610]$ \\
\hline Completeness to theta $=27.998$ & $100.0 \%$ \\
\hline Max. and min. transmission & 0.7868 and 0.1708 \\
\hline Refinement method & Full-matrix least-squares on $F^{2}$ \\
\hline Data/restraints/parameters & $1644 / 3 / 115$ \\
\hline Goodness-of-fit on $F^{2}$ & 1.072 \\
\hline Final R indices [I > 2 sigma (I)] & $\mathrm{R} 1=0.0404, \mathrm{wR} 2=0.0835$ \\
\hline $\mathrm{R}$ indices (all data) & $\mathrm{R} 1=0.0498, \mathrm{wR} 2=0.0888$ \\
\hline Absolute structure parameter & $0.01(2)$ \\
\hline Largest difference peak and hole & 0.343 and $-0.577 \mathrm{e} \cdot \mathrm{A}^{-3}$ \\
\hline
\end{tabular}

Bio-MOF-29 before and after drugs adsorption. The compound was heated from $0^{\circ} \mathrm{C}$ to $600^{\circ} \mathrm{C}$ at a heating rate of $10^{\circ} \mathrm{C}$ per minute. TGA plot before and after the drugs adsorption were compared. In Figure 3, the plot of copper glycinate before drugs adsorption shows first weight loss of $5 \%$ at $130^{\circ} \mathrm{C}$ which is due to the loss of coordinated water molecule. Then up to $250^{\circ} \mathrm{C}$ the framework remains intact with no weight loss. After that another weight loss is observed at $250^{\circ} \mathrm{C}$ due to the start of framework decomposition along with ligands and this decomposition continues till $300^{\circ} \mathrm{C}$ with a maximum weight loss of $65 \%$. Then the framework continues to decompose till $580^{\circ} \mathrm{C}$ with the formation of metal oxides.

The plot of Bio-MOF-29 after the terazosine adsorption shows a weight loss of $8 \%$ at $120^{\circ} \mathrm{C}$, which is due to the loss of drug molecules. Then the framework shows stability up to $150^{\circ} \mathrm{C}$. At $170^{\circ} \mathrm{C}$ another wieght loss of $12 \%$ is due to the loss of coordinated water molecule. After that the framework remains intact and at $340^{\circ} \mathrm{C}$ the framework starts decomposition which continues up to $380^{\circ} \mathrm{C}$ with 

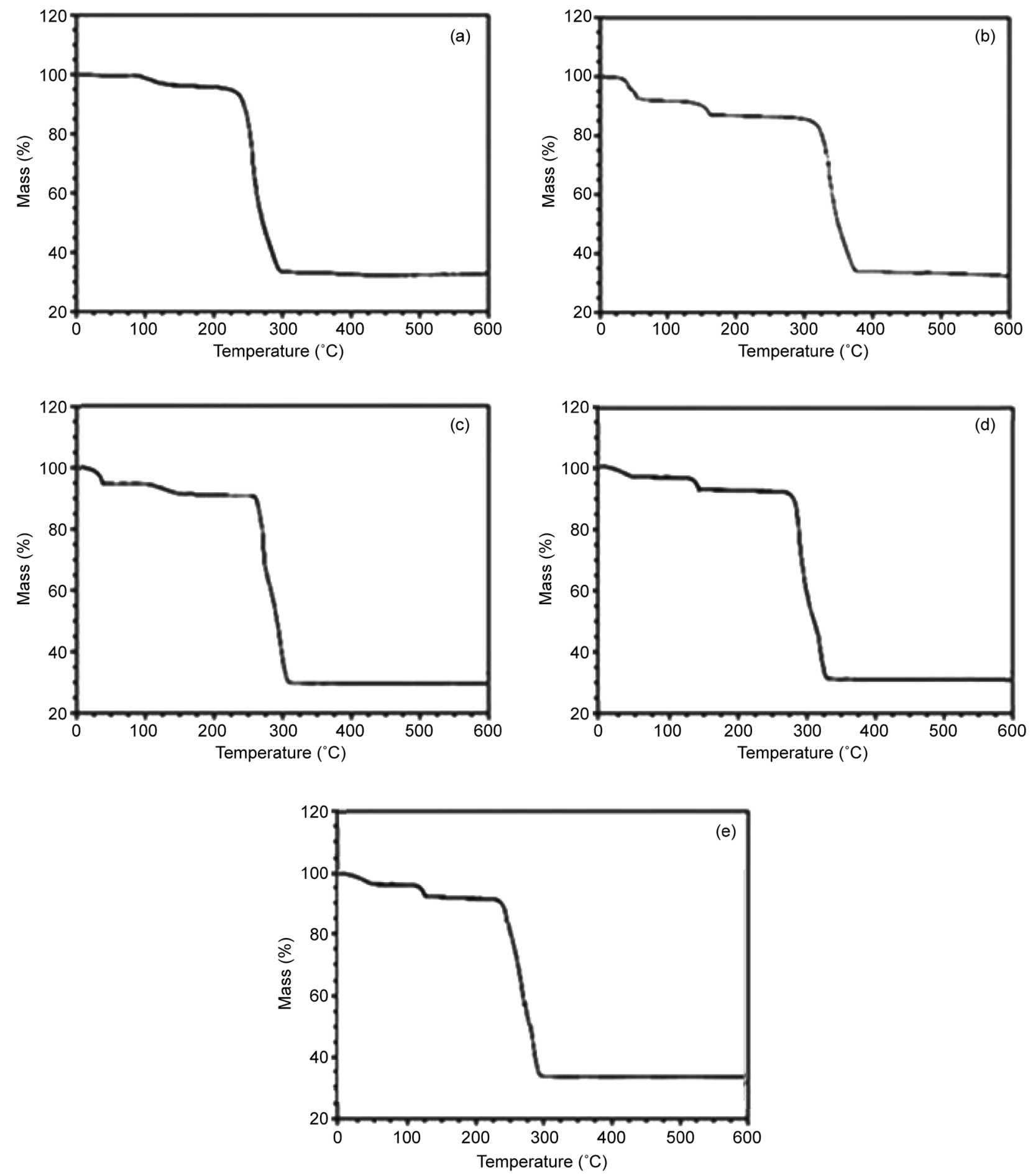

Figure 3. TGA plot of Bio-MOF-29 (a) before drugs adsorption, (b) after terazosine loading, (c) after telmisartan loading, (d) after glimpiride loading, (e) after rosuvastatin loading.

a weight loss of $60 \%$. Then up to $590^{\circ} \mathrm{C}$ the framework decomposes along with remaining terazosine contents.

TGA plot of telmisartan adsorbed Bio-MOF-29 shows a weight loss of $4 \%$ at $40^{\circ} \mathrm{C}$ which is due to the loss of telmisartan contents. Another weight loss of $8 \%$ at $150^{\circ} \mathrm{C}$ shows the loss of coordinated water molecule. Then the framework 
starts to decompose at $250^{\circ} \mathrm{C}$ which continues till $300^{\circ} \mathrm{C}$ with a maximum weight loss of $59 \%$. Then up to $550^{\circ} \mathrm{C}$ the whole framework decomposes along with remaining telmisartan contents.

A plot of glimpiride adsorbed Bio-MOF- 29 shows first weight loss $3 \%$ at $50^{\circ} \mathrm{C}$ which is due to the removal of glimpiride contents. Then up to $150^{\circ} \mathrm{C}$ the framework remains intact and at this temperature $9 \%$ weight loss is due to removal of coordinated water molecule. At $260^{\circ} \mathrm{C}$ the decomposition of the framework and ligands starts which continues till $300^{\circ} \mathrm{C}$ with weight loss of $55 \%$. Then the framework decomposition continues slowly with further weight loss until it completes at $560^{\circ} \mathrm{C}$ along with the decomposition of remaining glimpiride contents.

A plot of rosuvastatin adsorbed Bio-MOF-29 shows first weight loss 3\% at $48^{\circ} \mathrm{C}$ which is due to the removal of rosuvastatin contents. Then the framework shows stability up to $130^{\circ} \mathrm{C}$ and at this temperature $8 \%$ weight loss is due to removal of coordinated water molecule. The decomposition of the framework and ligands starts at $250^{\circ} \mathrm{C}$, which continues till $300^{\circ} \mathrm{C}$ with maximum weight loss of $50 \%$. Then the framework decomposition continues slowly and gradually with further weight loss until it completes at $550^{\circ} \mathrm{C}$ along with the decomposition of remaining drug contents.

\subsection{HPLC Peaks for the Estimation of Different Drugs in Bio-MOF-29}

For the sake of estimation of the drugs contents in the as synthesized material high Performance Liquid Chromatography was performed on a Waters 2695 separation module. All the details of HPLC parameters used for HPLC studies have been given (as supporting information).

$0.18 \mathrm{~g} / \mathrm{g}$ material of terazosine contents have been detected in Bio-MOF-29. Maximum amount of released terazosine was estimated in the aliquot of water containing released drug after one day and this amount decreased slowly so that no drug contents were estimated in the aliquot of water containing released drug after five days, whereas the amount of telmisartan was found $0.15 \mathrm{~g} / \mathrm{g}$ in BioMOF-29. The amount of adsorbed telmisartan was released at intervals from the material and no telmisartan contents were found in the material after seven days.

For glimpiride the amount of adsorbed drug calculated through HPLC was $0.03 \mathrm{~g} / \mathrm{g}$ material of Bio-MOF-29. This amount of adsorbed drug was fully released from the material within three days.

$0.05 \mathrm{~g} / \mathrm{g}$ material of rosuvastatin drug was adsorbed in Bio-MOF-29 and this amount of adsorbed drug was remained in the channels of the material for three days only with its slow release at intervals and after three days no drug contents were detected in the material.

\subsection{Powder XRD Patterns of Bio-MOF-29}

Drugs adsorption experiments performed on Bio-MOF-29 reveal that guest drug molecules can be adsorbed in the pores without loss of framework crystallinity. Powder XRD pattern after drug adsorption as shown in Figure 4, has revealed 


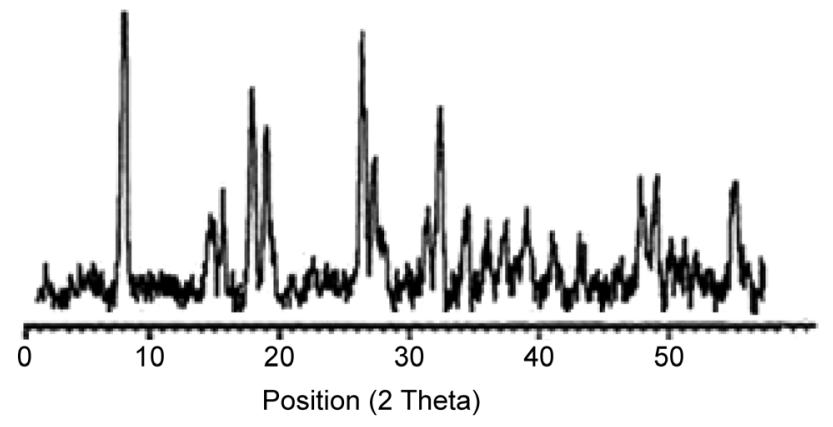

(a)

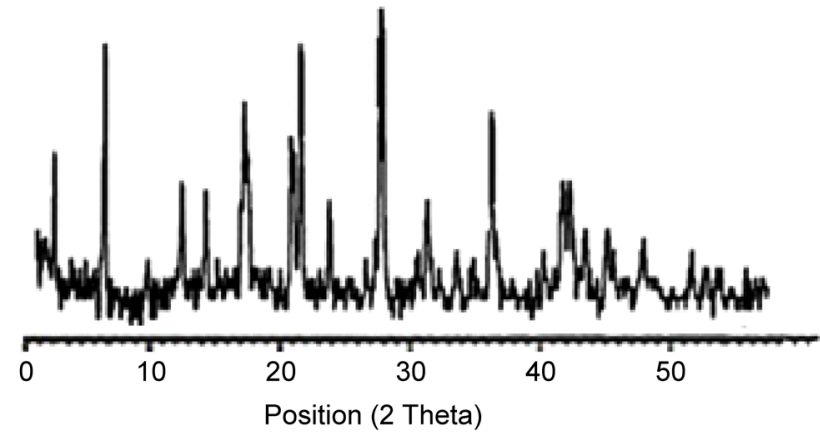

(c)

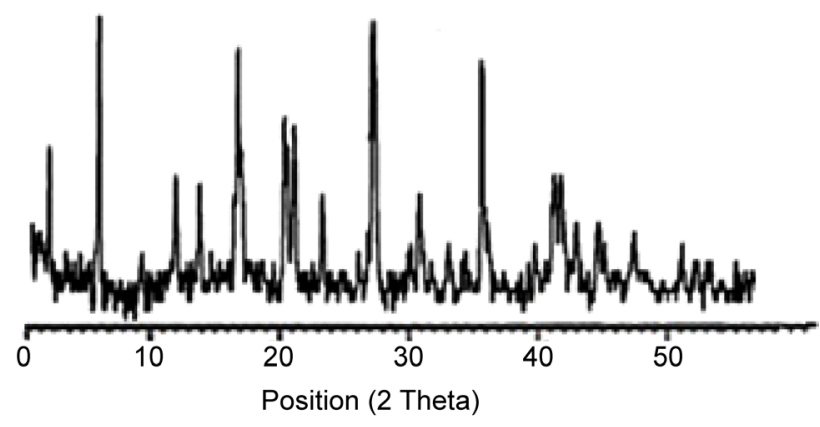

(b)

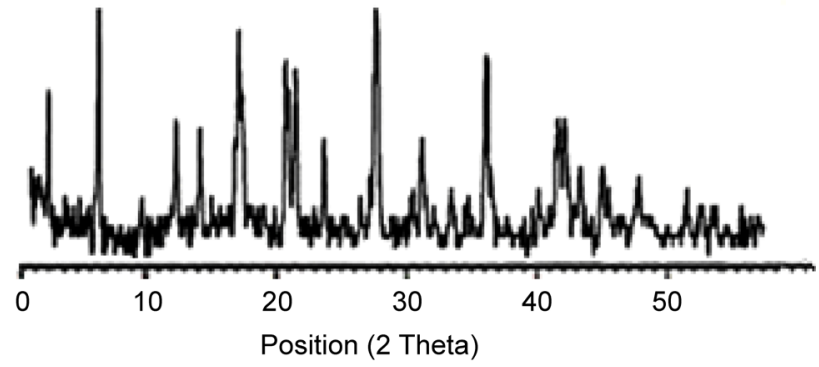

(d)

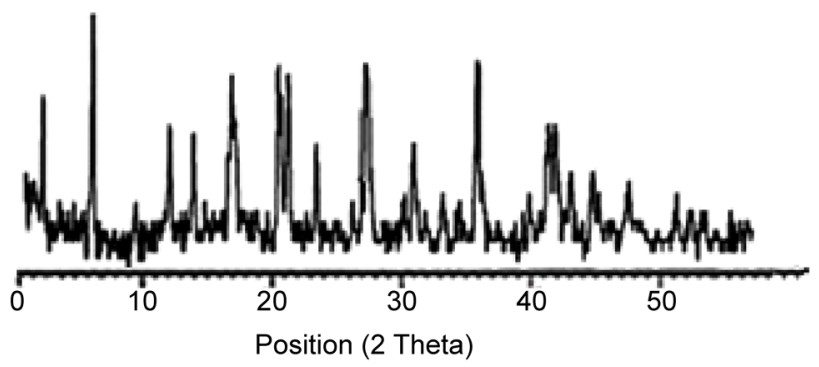

(e)

Figure 4. PXRD pattern of Bio-MOF-29 (a) Pure (b) After terazosine loading, (c) After telmisartan loading, (d) After glimpiride loading, (e) After rosuvastatin loading.

the crystalline integrity of Bio-MOF-29 even after soaking the material in water for several days.

\section{Experimental Section}

Bio-MOF-29 has been synthesized by hydrothermal method.Thermogravimetric analysis was performed on SDT Q600, thermo gravimetric instrument. FT-IR spectra were obtained on Shimadzu 8400 FT-IRby preparing KBr pellets. Powder XRD Patterns were recorded onBruker $\mathrm{D}_{2}$ Phaser. HPLC studies of the drugs soaked Bio-MOF-29 were carried out on HPLC system, Waters 2695 separation module to estimate the amount of drugs adsorbed and also to observe its slow release after intervals.

\subsection{Hydrothermal Synthesis of Bio-MOF-29}

Glycine $(0.15 \mathrm{~g}, 0.2 \mathrm{mmol})$ and copper chloride, $\mathrm{CuCl}_{2} \cdot 2 \mathrm{H}_{2} \mathrm{O}(0.35 \mathrm{~g}, 0.2 \mathrm{mmol})$ 
were dissolved in $10 \mathrm{~mL}$ water taken in a beaker. This solution was well stirred for half an hour. $10 \mathrm{pH}$ of solution was obtained by adding sodium carbonate solution. This solution was transferred to a $23-\mathrm{mL}$ teflon lined autoclave. The autoclave was placed in oven at $150^{\circ} \mathrm{C}$ for three days. Fine quality blue colored rod-like crystals were obtained from it. These crystals were collected, washed with water and were dried.

\subsection{Preparation of Drug Soaked Samples of Bio-MOF-29}

Copper glycinate (Bio-MOF-29) was loaded with terazosine hydrochloride by soaking it in 0.1 molar solution of drug. The procedure followed was that after twenty four hours the drug solution was removed and fresh drug solution was added to copper glycinate (Bio-MOF-29). This process was repeated for twenty days on regular basis. After twenty days of soaking the material in drug solution, one portion of the material ( $1.0 \mathrm{~g}$ ) was evaluated for the drugs adsorption studies through TGA and PXRD Patterns.

For HPLC studies the other portion of the drug soaked material $(1.0 \mathrm{~g})$ was placed in pure water $(5 \mathrm{~mL})$ in a vial and aliquots of water/drug loaded BioMOF-29 suspensions were separated after one day. Then same amount of pure water was added to drug soaked Bio-MOF-29 and water/drug soaked Bio-MOF29 suspensions were separated after three days. The same process was repeated after one, three, five, seven, nine, fifteen days of soaking and all samples separated were saved for HPLC studies. All this procedure was also repeated for Bio-MOF-2 9 by using other three drugs (telmisartane, glimpiride and rosuvastatin) as well.

Elemental Analysis of the compound Bio-MOF-29, Theoretical; $\mathrm{Cu}=27.83 \%$, $\mathrm{C}=20.99 \%, \mathrm{H}=3.96 \%, \mathrm{~N}=12.30 \%$.

Experimental; $\mathrm{Cu}=27.78 \%, \mathrm{C}=19.87 \%, \mathrm{H}=3 \cdot 34 \%, \mathrm{~N}=12 \cdot 25 \%$.

FT-IR Spectra of Bio-MOF-29:

3282.9 (br) $\mathrm{cm}^{-1}, 3232.55$ (br) $\mathrm{cm}^{-1}, 2740.30(\mathrm{~m}) \mathrm{cm}^{-1}, 1647.1(\mathrm{~s}) \mathrm{cm}^{-1}, 1608.5$ (m) $\mathrm{cm}^{-1}, 1500.5(\mathrm{~s}) \mathrm{cm}^{-1}, 11467.7(\mathrm{~s}) \mathrm{cm}^{-1}, 1384.8(\mathrm{~m}) \mathrm{cm}^{-1}, 1197.7(\mathrm{~s}) \mathrm{cm}^{-1}$, $1151.4(\mathrm{~m}) \mathrm{cm}^{-1}, 840.9(\mathrm{~s}) \mathrm{cm}^{-1}, 507.2(\mathrm{~s}) \mathrm{cm}^{-1}$.

\section{Conclusion}

In conclusion, the present study directs towards the hydrothermal synthesis of a bio metal organic framework based on a bio molecule and a biocompatible metal cation and its successful use for in vitro drugs adsorption studies. In vitro drug adsorption studies in the bio-molecular building blocks of the new material will open new gateways for in vivo drugs adsorption experiments for the welfare of humans. It is expected that the present work will enhance the use of bio-molecules for the construction of bio-metal organic frameworks for the sake of their use in the medical applications.

\section{References}

[1] Rieter, W.J., Taylor, K.M.L., An, H.Y., Lin, W.L. and Lin, W. (2006) Nanoscale 
Metal-Organic Frameworks as Potential Multimodal Contrast Enhancing Agents. J. Am. Chem. Soc., 128, 9024-9025.

[2] Horcajada, P., Serre, C., Vallet-Regi, M., Sebban, M., Taulelle, F. and Ferey, G. (2006) Metal-Organic Frameworks as Efficient Materials for Drug Delivery. Angew. Chem. Int. Ed., 45, 5974-5978.

[3] McKinlay, A.C., Morris, R.E., Horcajada, P., Ferey, G., Gref, R., Couvreur, P. and Serre, C. (2010) BioMOFs: Metal-Organic Frameworks for Biological and Medical Applications. Angew. Chem., Int. Ed., 49, 6260-6276.

[4] Horcajada, P., Serre, C., Maurin, G., Ramsahye, N.A., Balas, F., Vallet-Regi, M., Sebban, M., Taulelle, F. and Ferey, G. (2008) Flexible Porous Metal-Organic Frameworks for a Controlled Drug Delivery. J. Am. Chem. Soc., 130, 6774-6780.

[5] Ananthoji, R., Eubank, J.F., Nour, F., Motaki, H. and Eddaudi, M. (2011) Symbiosis of Zeolite-Like Metal-Organic Frameworks (rho-ZMOF) and Hydrogels: Composites for Controlled Drug Release. J. Mat. Chem., 21, 9587-954.

[6] Bernini, M.C., Jimenez, D.F., Pasinetti, M., Ramirez, A.J. and Snurr, R.Q. (2014) Screening of Bio-Compatible Metal-Organic Frameworks as Potential Drug Carriers Using Monte Carlo Simulations. J. Mater. Chem. B., 2, 766-774.

[7] Lee, H.L., Kampf, J.W., Park, K.S. and Marsh, E.N.G. (2008) Covalent Metal? Peptide Framework Compounds That Extend in One and Two Dimensions. Cryst. Growth Des., 8, 296-303.

[8] Anokhina, E.V., Go, Y.B., Lee, Y., Vogt, T. and Jacobson, A.J. (2006) Chiral ThreeDimensional Microporous Nickel Aspartate with Extended $\mathrm{Ni}^{-}, \mathrm{O}^{-}$, Ni Bonding. J. Am. Chem. Soc., 128, 9957-9962.

[9] Garcia-Teran, J.P., Castillo, O., Luque, A., Garcia-Couceiro, U., Roman, P. and Lezama, L. (2004) One-Dimensional Oxalato-Bridged $\mathrm{Cu}(\mathrm{II}), \mathrm{Co}(\mathrm{II})$, and $\mathrm{Zn}$ (II) Complexes with Purine and Adenine as Terminal Ligands. Inorg. Chem., 43, 45494551.

[10] Navarro, J.A.R. and Lippert, B. (1999) Simple 1:1 and 1:2 Complexes of Metal Ions with Heterocycles as Building Blocks for Discrete Molecular as Well as Polymeric Assemblies. Coord. Chem. Rev., 4, 653-667.

[11] Makinlet, A.C., Morris, R., Horkajada, P., Ferrey, F., Gref, R., Couvreur, P. and Sere, C. (2011) Metal-Organic Frameworks in Biomedicine. Chemical Reviews, 112, $1232-1268$.

[12] Li, M., Kim, H.S., Tian, L., Yu, M.K., Jon, S. and Mon, W.K. (2012) Comparison of Two Ultrasmall Superparamagnetic Iron Oxides on Cytotoxicity and MR Imaging of Tumors. Theranostics, 2, 76-85. https://doi.org/10.7150/thno.3462

[13] Bowmaker, G.A. (2013) Solvent-Assisted Mechanochemistry. Chemical Communications, 49, 334-348. https://doi.org/10.1039/C2CC35694E

[14] Bradshaw, D., Grai, A. and Huo, J. (2013) Metal-Organic Framework Growth at Functional Interfaces: Thin Films and Composites for Diverse Applications. Chemical Society Reviews, 41, 2344-2381. https://doi.org/10.1039/C1CS15276A

[15] Purohit, C.S. and Verma, S. (2006) A Luminescent Silver-Adenine Metallamacrocyclic Quartet. Journal of the American Chemical Society, 128, 400-401. https://doi.org/10.1021/ja056452z

[16] Sun, C., Qin, C., Wang, X.Z. and Su, M. (2013) Metal-Organic Frameworks as Potential Drug Delivery Systems. Angewandte Chemie International Edition, 10, 89101.

[17] Burke, L.E., Dunbar-Jacob, J.M. and Hill, M.N. (1997) Compliance with Cardiovascular Disease Prevention Strategies: A Review of the Research. Anal. Behav. 
Med., 239-263.

[18] Demessence, A., Alessandro, D.M., Foo, M.L. and Long, J.R. (2009) Strong $\mathrm{CO}_{2}$ Binding in a Water-Stable, Triazolate-Bridged Metal-Organic Framework Functionalized with Ethylenediamine. Journal of the American Chemical Society, 131, 8784-8790. https://doi.org/10.1021/ja903411w

[19] Imaz, I., Marthenis, R., Solefront, I., Rosi, N.L. and Mespoch, D. (2011) Metal-Biomolecule Frameworks (MBioFs). Chemical Communications, 47, 7287-7302.

https://doi.org/10.1039/c1cc11202c

[20] Rosi, N.L., Kim, J., Eddaoudi, M., Chen, B.L., O’Keeffe, M. and Yaghi, O.M. (2005) Rod Packings and Metal-Organic Frameworks Constructed from Rod-Shaped Secondary Building Units. Journal of the American Chemical Society, 127, 15041518. https://doi.org/10.1021/ja045123o

[21] Chen, Y. and Jiang, J. (2010) A Bio-Metal-Organic Framework for Highly Selective $\mathrm{CO}_{2}$ Capture: A Molecular Simulation Study. ChemSusChem, 3, 982-988. https://doi.org/10.1002/cssc.201000080

[22] An, J., Geib, S.J. and Rosi, N.L. (2009) Cation-Triggered Drug Release from a Porous Zinc-Adeninate Metal-Organic Framework. Journal of the American Chemical Society, 131, 8376-8377. https://doi.org/10.1021/ja902972w

[23] An, J., Geib, S.J. and Rosi, N.L. (2010) High and Selective $\mathrm{CO}_{2}$ Uptake in a Cobalt Adeninate Metal-Organic Framework Exhibiting Pyrimidine- and Amino-Decorated Pores. Journal of the American Chemical Society, 132, 38-39. https://doi.org/10.1021/ja909169x

[24] Vaidhyanathan, R., Bradshaw, D., Rebilly, J.N., Barrio, J.P., Gould, J.A., Berry, N.G. and Rosseinsky, M.J. (2006) A Family of Nanoporous Materials Based on an Amino Acid Backbone. Angewandte Chemie International Edition, 45, 6495-6499. https://doi.org/10.1002/anie.200602242

[25] Beurskens, P.T., Admiraal, G., Bosman, W.P., Gelder, R., Israel, R. and Smits, J.M.M. (1994) The DIRDIF-94 Program System, Technicall Report of the Crystallography Laboratory. University of Nijmegen, Nijmegen.

[26] Sheldrick, G.M. (1997) A Program for Refinement of Crystal Structures. SHELXL 97, University of Göttingen, Göttingen.

\section{Scientific Research Publishing}

Submit or recommend next manuscript to SCIRP and we will provide best service for you:

Accepting pre-submission inquiries through Email, Facebook, LinkedIn, Twitter, etc. A wide selection of journals (inclusive of 9 subjects, more than 200 journals)

Providing 24-hour high-quality service

User-friendly online submission system

Fair and swift peer-review system

Efficient typesetting and proofreading procedure

Display of the result of downloads and visits, as well as the number of cited articles

Maximum dissemination of your research work

Submit your manuscript at: http://papersubmission.scirp.org/

Or contact ojic@scirp.org 